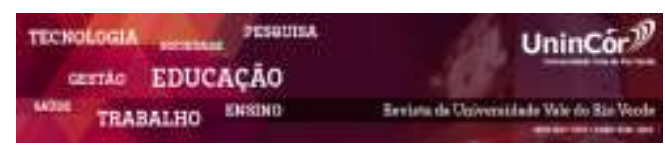

Revista da Universidade Vale do Rio Verde ISSN: 1517-0276 / EISSN: 2236-5362 Vol. $16 \mid$ n. $1 \mid$ Ano 2018

Paulo Henrique Pinho de Oliveira CEFET-RJ paulo.pinho@cefet-rj.br

Marco Aurélio Carino Bouzada UNESA marco.bouzada@estacio.br

\section{A INFLUÊNCIA DOS ESTILOS DE APRENDIZAGEM DE KOLB SOBRE A EXPERIÊNCIA DE ALUNOS DE GRADUAÇÃO EM ADMINISTRAÇÃO NO CONTEXTO DAS SIMULAÇÕ̃S EMPRESARIAIS}

\section{RESUMO}

A eficiência da metodologia de Jogos de Negócios no ensino já não é mais questionada por muitos autores. No entanto, se estudarmos este tópico utilizando os conhecimentos da psicologia sobre aprendizagem vivencial, encontramos uma lacuna pouco abordada na literatura sobre simulações empresariais: as influências que um integrante pode exercer no aprendizado de um colega de equipe durante uma simulação de jogos de negócios. Seria possível afirmar que um aluno que tem preferência por tomar decisões por instinto e sem planejamento pode atrapalhar o aprendizado de um colega de equipe que prefere analisar a situação com calma antes de tomar uma decisão? Haveria talvez alguma possível combinação entre os estilos de aprendizagem que, se estiverem juntos na mesma equipe, o processo de aprendizado seja alterado? Para responder estas questões foi utilizada uma metodologia qualitativa, com entrevistas semiestruturadas, e análise de conteúdo, com alunos do último período da graduação em administração em duas universidades na cidade do Rio de Janeiro. O resultado obtido foi que, pela ótica dos estilos de aprendizagem de Kolb, não há influência de um aluno no aprendizado de seus colegas de equipe, mas fica evidente, pela opinião dos participantes, que há influência da equipe sobre seu aprendizado na medida em que o trabalho em equipe se teria mostrado mais bem-sucedido do que o que se obteria em atividade individual.

Palavras-chave: jogos de negócios; aprendizagem vivencial; estilos de aprendizagem; Kolb; equipe.

\section{THE INFLUENCE OF KOLB'S LEARNING STYLES ON THE EXPERIENCE OF IN ADMINISTRATION GRADUATION STUDENTS WITHIN BUSINESS SIMULATIONS CONTEXT}

\begin{abstract}
The efficiency of business game methodology is hardly ever questioned nowadays. However, considering psychological knowledge about experiential learning, a gap can be found that is rarely mentioned in business simulation literature: the influence that a student may have on a teammate's knowledge during a business simulation game. Is it possible to state that a student who prefers to make decisions by instinct and without planning can hinder a co-worker's learning process in case the latter prefers to carefully analyze a situation before coming to a decision? Could there be any possible arrangement of learning styles that is
\end{abstract}


capable of changing the learning experience if put together in the same team? In order to answer these questions using a qualitative approach, this dissertation applied semi-structured interviews and content analysis to last-term students of business administration from two universities in Rio de Janeiro. In view of Kolb's learning styles, the final result showed that there was no influence of a particular students on their teammates' learning process, though it was clear, taking the opinion of the students interviewed into account, that the team exerts some influence on their learning processes since teamwork appears to be more successful than what would be accomplished through individual work.

Keywords: business game; experiential learning; learning styles; Kolb; teams.

\section{Recebido em: 18/02/2018 - Aprovado em: 18/05/2018 - Disponibilizado em: 15/07/2018}

\section{INTRODUÇÂO}

Os cursos de graduação e pós-graduação na área de administração no Brasil têm tanta representatividade que, segundo os dados divulgados pelo INEP (ABNT, 2015), os cursos de "Gerenciamento e administração" possuíram 1.299.065 matrículas, $16 \%$ do total Brasil. Para fins de comparação, a tradicional carreira de Medicina com todas as subdivisões (enfermagem, odontologia, etc.) representou cerca de $14 \%$; e outro curso tradicional, como o de Direito, teve pouco mais de $10 \%$ das matrículas totais. Diante destes dados, se torna cada vez mais relevante estudar novas metodologias que possam ser aplicadas ao ensino da administração. Assim como Rodrigues e Sarrapio (2018) demonstraram com o uso do xadrez no ensino básico, a metodologia de jogos de negócios para proporcionar ao aluno do ensino superior uma experiência bem diferente, haja vista que, ao participar de uma simulação empresarial, o aluno tem contato com prática semelhante à que um futuro administrador terá em seu dia a dia.
Estas simulações empresariais têm sido bastante estudadas por diversos autores (SAUAIA, 1997; LACRUZ; VILLELA, 2005; MOTA; MELO, PAIXÃO, 2012; ALVES, 2015). O objetivo incialmente era demonstrar o quanto a nova metodologia poderia ser melhor do que o ensino tradicional. Com o passar do tempo, a maioria dos autores já não questionava mais a eficiência deste método, e o foco passou a ser o desenvolvimento da metodologia para melhorar a experiência do aluno durante as simulações.

A grade curricular dos cursos de Administração possui disciplinas bastante distintas umas das outras; algumas mais voltadas para as ciências exatas, outras, para as ciências humanas. Seguindo essa característica multidisciplinar do curso, os estudos sobre a metodologia baseada em jogos se aproveitaram de alguns conhecimentos da psicologia que lhe pareciam bastante úteis: em particular a aprendizagem vivencial. Vários autores já estudaram e comprovaram esta relação entre os jogos de negócios e a aprendizagem vivencial, como por exemplo, ROGERS (1972, citado por SAUAIA, 1997). O autor concluiu em sua 
pesquisa que a aprendizagem cognitiva e afetiva dos alunos, no desempenho das tarefas na simulação, lhes proporcionou uma visão organizacional mais sistêmica, que pode representar um ganho real no aprendizado destes alunos, preparando-os para a vida profissional.

Atualmente existem diversos cursos de graduação e pós-graduação com uma disciplina baseada nas simulações empresariais, mas apesar de tantas pesquisas sobre a relevância do tema, é possível perceber que pouco se estuda a interação entre os participantes da simulação, que normalmente é realizada em equipes. Para se ter uma ideia da relevância de estudar a relação entre os participantes de uma equipe de jogos de negócios, quando Mota, Melo e Paixão (2009) realizaram suas pesquisas perguntando aos alunos o que são Jogos de Empresas, as opiniões foram variadas, mas se concentraram em três aspectos centrais: o treinamento do processo decisório, a vivência de experiências práticas, e o desenvolvimento de habilidades para o trabalho em equipe.

Corroborando a importância de se estudar as equipes participantes de jogos de empresas, Madkur, Mrtvi e Lopes (2008) apresentaram um estudo sobre os estilos de aprendizagem e as equipes durante uma simulação de jogos empresariais. Na ocasião, os autores utilizaram métodos quantitativos, com uma amostra de 137 alunos, sendo o objetivo identificar a relação entre os estilos de aprendizagem e o comportamento das equipes no processo de análise e tomada de decisão, além de estudar o comportamento individual no mesmo processo e as percepções dos participantes sobre a contribuição da metodologia para seu aprendizado. Os autores concluíram que, mesmo estudando equipes homogêneas e heterogêneas, o comportamento das equipes analisadas não foi significativamente diferente, ou seja, os autores acreditavam que encontrariam algum tipo de padrão de comportamento nas equipes de acordo com seus respectivos estilos de aprendizagem, mas isso não foi confirmado com o nível de significância de $5 \%$ proposto pelos autores. Vale destacar que todas as equipes tiveram a percepção de que o jogo de empresas contribuiu substancialmente para desenvolver nos participantes um maior interesse pela estratégia.

\subsection{Formulação do Problema}

No contexto abordado por Madkur, Mrtvi e Lopes (2008), esta pesquisa teve como objetivo ajustar o foco para as relações entre os participantes de uma mesma equipe. Ou seja, tomando-se como base o resultado que estes autores não conseguiram provar quantitativamente, seria possível identificar através de uma pesquisa qualitativa, se um aluno é capaz de influenciar o aprendizado de seus colegas de equipe? Seria possível afirmar que um aluno que tem preferência por decidir intuitivamente e sem planejamento, pode atrapalhar o aprendizado de um colega de equipe que prefere analisar a situação com calma antes de tomar uma decisão? Será que existe alguma influência do estilo de aprendizagem na relação entre os alunos de uma mesma equipe? $\mathrm{E}$ ainda, uma questão muito importante: seria possível dizer que algum determinado estilo de aprendizagem tem uma melhor experiência de aprendizado quando está na mesma equipe de um outro determinado estilo? Ou algum estilo de aprendizagem é capaz de atrapalhar os demais em seu processo de aprendizado? 
O objetivo principal desta pesquisa foi compreender a relação entre os estilos de aprendizagem dentro de cada equipe numa disciplina de simulações empresariais, verificando se há indícios de que o aprendizado de um aluno pode ser influenciado pelo perfil de aprendizagem de outro integrante da mesma equipe.

Avaliar esta relação entre os alunos de uma equipe com base em seus estilos não é uma questão que pode contribuir somente para o desenvolvimento de práticas acadêmicas nas disciplinas de jogos de negócios. Há também uma contribuição relevante para o dia a dia das empresas e de qualquer gestor que precise montar uma equipe para desempenhar algum projeto em conjunto.

\section{QUADRO CONCEITUAL SUPOSIÇÃO DE PESQUISA}

Dentro da literatura acerca dos diferentes estilos de aprendizagem, existem autores que apresentam classificações consagradas de estilos de aprendizagem, como Kolb (1984), Keirsey e Bates (1984) e Felder e Silvermann (1988).

O estudo de Kolb (1984) foi escolhido para ser utilizado nesta pesquisa por ter sido o pioneiro no estudo dos estilos de aprendizagem, e ser bastante citado em pesquisas da psicologia sobre o tema. $\mathrm{O}$ autor estabeleceu um modelo representado por um círculo, com o intuito de deixar claro que se tratava de um ciclo contínuo composto por quatro etapas: EC - experiência concreta; OR - observação reflexiva; CA conceituação abstrata; e EA - experimentação ativa. O Ciclo de Aprendizagem Vivencial de Kolb (1984) indica que na maioria das vezes o processo de aprendizagem começa com uma ação que se desdobrará em efeitos que serão percebidos pelos participantes (EC). Com base nesta experiência é possível compreender o que aconteceu, de tal modo que se acontecer novamente tal ação, nas mesmas circunstâncias, será possível se antecipar aos efeitos que ocorrerão (OR). Este aprendizado, e a construção mais abstrata do que aconteceu sob tais circunstâncias, permite uma generalização do fato (CA), permitindo tal nível de entendimento que o indivíduo é capaz de tomar uma nova ação sob novas circunstâncias (EA).

Kolb (1999) também desenvolveu um questionário, conhecido como "inventário de estilos de aprendizagem" (IEA), que permitiu a identificação de características comuns em determinadas pessoas para aprender. Ou seja, baseado nas respostas do IEA, é possível identificar o perfil de aprendizagem de uma pessoa, e consequentemente identificar suas preferências sobre seu processo de aprendizado.

O significado de cada estilo de aprendizagem, na prática, segundo Kolb (1999) está descrito a seguir:

Divergentes: são pessoas que preferem ver situações concretas de diferentes pontos de vista, normalmente se dão melhor com atividades mais criativas porque buscam "pensar fora da caixa". Interessam-se por diversas informações e costumam se adequar melhor em profissões como terapeutas, assistentes sociais, artistas, músicos, etc. O professor neste caso deve exercer um papel mais motivador para o aluno com este perfil. Em resumo, são pessoas que gostam de pensar e avaliar a situação sob diferentes pontos de vista. Normalmente são os que apresentam ideias mais criativas e diferentes. (KOLB, 1999; KOLB, BOYATZIS \& MAINEMELIS, 2001). 
"Por uma excessiva polarização as múltiplas alternativas podem impedir a tomada de decisões nos indivíduos que adotam o estilo 'divergente' de aprendizagem; parecem mais aptos para as organizações de serviços e para as artes. Os carentes desse estilo encontram dificuldades para gerar ideias, reconhecer os problemas e as oportunidades. " (PEREIRA, 2005, p. 23).

Assimiladores: têm mais habilidades na construção de modelos abstratos e teóricos, são pessoas que gostam de uma quantidade maior de informações desde que expostas de maneira mais concisa e lógica. São pessoas que conseguem reunir muitas informações de maneira lógica para facilitar o entendimento de um problema; na busca pela solução, suas decisões se baseiam em modelos reduzidos do mundo real. São mais facilmente encontrados em profissões como professores, escritores, advogados etc. Para este tipo de aluno, o professor deve exercer o papel de um especialista, auxiliando-o na compreensão das informações e na construção lógica do problema. Normalmente, são pessoas mais voltadas para as carreiras que envolvem a ciência e a informação. (KOLB, 1999).

'Se o componente 'assimilador' é excessivo, podem tender a construir 'castelos no ar' e serem incapazes de aplicar seus conhecimentos em situações práticas. Por outro lado, os que carecem do estilo de aprendizagem de Assimilação são incapazes de aprender com seus erros e não enfocam os problemas de maneira sistemática. " (CERQUEIRA, 2008).
Convergentes: Este estilo, segundo VALENTE et al (2008), é exatamente o oposto daquele dos divergentes. Estes partem de sua conceituação abstrata da situação para transformá-la em experimentação ativa através da prática. São pessoas mais orientadas para atividades técnicas ou práticas e menos teóricas, como "tentativa e erro", possuindo características mais favoráveis a participar de simulações ou tarefas em laboratórios. Normalmente usam o raciocínio dedutivo para aplicar suas ideias e costumam ser bastante produtivos na definição de problemas. Em geral, costumam se dedicar a profissões nas áreas tecnológicas como engenheiros, físicos, ou talvez médicos. O professor deve assumir o papel de um treinador para os alunos de perfil convergente, garantindo um ambiente em que lhes seja permitido assumir os riscos da situação como se fossem reais, mas com a segurança de ser uma simulação. (KOLB, 1999).

Acomodadores: são pessoas que gostam mais de aprender fazendo, de preferência algo que seja claramente útil para seu futuro profissional (experimentação ativa e concreta). Seguem mais seus instintos do que teorias e estudos lógicos, mas confiam nos outros para realizar análises mais complexas de relatórios. Uma carreira onde se encontra mais este perfil é a do marketing. Para um aluno com este perfil de aprendizagem, o professor deve exercer um papel de facilitador, tentando maximizar suas oportunidades, para que naturalmente o aluno faça as conexões necessárias entre a teoria e a prática. Normalmente são pessoas que apresentam características de liderança, praticidade e disposição para assumir riscos. (KOLB, 1999). 
"Os que têm um excessivo componente 'acomodador' podem usar sua energia em melhorias triviais em seu trabalho, que podem resultar em um grande fracasso ou algo equivocado. Intuitivos, resolvem os problemas por ensaio e erro". (CERQUEIRA, 2008).

Randel et al. (1992) chama atenção para algo que está diretamente associado ao objetivo desta pesquisa: o nível de aprendizagem proposto em qualquer disciplina que utilize a metodologia baseada em jogos está condicionado ao grau de participação do aluno no jogo. Ou seja, por mais interessante que seja a simulação utilizada, e por melhor que seja o professor que aplicar a metodologia, não há garantias de que haverá um resultado mais eficiente no aprendizado dos alunos, se não houver sua efetiva participação na simulação.

Silva et al. (2012) identificaram falta de interesse de alguns alunos quando lhes é concedida mais autonomia para a tomada de decisão na simulação.

Motta, Melo e Paixão (2009) também abordaram esta questão da participação individual de um estudante por meio de uma simulação de jogos de empresas. Os autores consideraram que esta é uma fragilidade da disciplina, por presumir que o nível de participação e aprendizado será igual entre os participantes.

Bouzada (2017) aplicou uma simulação especificamente sobre a área logística, e os resultados seguiram a mesma tendência de que a efetiva participação do aluno é essencial para que se obtenha o aprendizado esperado. Naquela pesquisa intitulada de "Laboratório de
Logística", o autor percebeu que se considerasse todos os alunos da turma, não havia uma relação direta entre o bom resultado na simulação e a maior assimilação dos conhecimentos abordados. No entanto, ao restringir sua análise aos alunos que efetivamente participaram das atividades, sua hipótese não foi rejeitada, e aqueles que mais assimilaram os conteúdos foram os que tiveram melhores resultados na simulação.

Diante destas informações, apesar de não ser muito comum esta preocupação dos docentes com a adequação individual do conteúdo, ou método, às diferenças de cada aluno, parece fazer sentido que os professores procurem novos métodos de abordagem que contribuam para que o aluno tenha melhor aproveitamento em suas aulas. Nesta mesma linha de raciocínio, Dias et al. (2013) utilizaram os estilos de aprendizagem de Felder e Silverman (1988), em um estudo quantitativo, e conseguiram encontrar pequenas diferenças no aprendizado individual de cada estilo de aprendizagem entre os alunos que cursaram a disciplina Jogo de Empresas. Resumidamente, os autores identificaram que os alunos que têm preferência visual possuem aproveitamento maior na disciplina, e os alunos mais ativos tiveram dificuldade de realizar a "observação reflexiva" para assimilar melhor o conteúdo abordado. Estes resultados reforçam a importância de que os professores explorem melhor o perfil dos alunos ao determinar os conteúdos e mecânicas que serão utilizados em sala de aula.

Madkur, Mrtvi e Lopes (2008) por exemplo, não identificaram diferença de comportamento nas equipes com estilos de aprendizagem diferentes. Nessa linha, a pesquisa atual pretende verificar a suposição de que, ao se 
combinarem determinados estilos de aprendizagem em uma mesma equipe de uma simulação usando jogos empresariais, há uma relação complementar potencializando o aprendizado dos alunos. Ou seja, é possível supor que nas diferentes combinações entre os estilos de aprendizagem, existam algumas nas quais um aluno identificado pelo estilo "a" ajude o aluno do estilo "b" a compreender o conteúdo de forma mais rápida do que se estivesse sozinho na simulação. Assim como também pode haver interações negativas, nas quais um aluno dificulta o aprendizado de seu colega de equipe.

Por exemplo, pode-se conjecturar que o aluno com o perfil assimilador tenha dificuldades de se relacionar com o de perfil acomodador, por exemplo, uma vez que o primeiro gosta de criar modelos abstratos e teóricos para solucionar um problema, enquanto que o segundo segue mais seus instintos. Ou considerar que o fato de o perfil divergente gostar de analisar por diferentes pontos de vista talvez o torne aquele que mais bem se adapta às diferenças de aprendizagem dos outros estilos.

\section{METODOLOGIA}

A pesquisa foi realizada ao longo do ano letivo de 2017, com todos os alunos das turmas de administração nas universidades Candido Mendes e CEFET. A primeira parte deste processo foi a aplicação do inventário de Kolb para identificação dos estilos de aprendizagem. Os alunos responderam as doze sentenças e foram identificados conforme seus respectivos estilos de aprendizagem.

Após alguns meses de participação na disciplina utilizando o mesmo simulador, e orientados pelo mesmo professor, alguns alunos foram selecionados para a etapa seguinte: as entrevistas. Para selecionar esta amostra foram considerados os resultados obtidos por Bouzada (2017), quando foi demonstrado que os alunos que não participam efetivamente da simulação não conseguem assimilar tantos conteúdos quanto os que participam mais ativamente; portanto, para selecionar os alunos que seriam entrevistados o professor relacionou somente os alunos que realmente participaram na disciplina. Este critério foi aplicado apenas para não selecionar alunos com excesso de faltas, ou aqueles que mesmo presentes em sala de aula nitidamente não apresentaram interesse pela simulação e não interagiram com a equipe.

Um segundo critério utilizado foi o estilo de aprendizagem, com o objetivo de obter aproximadamente o mesmo número de cada estilo, porém no final a amostra que realmente foi utilizada por esta pesquisa sofreu pequenas alterações devido às dificuldades individuais dos alunos que não puderam comparecer nos dias e horários agendados para a entrevista.

A maioria dos autores que estudam sobre as simulações empresariais opta por estudos quantitativos para verificar suas hipóteses, e esta pode ser a principal contribuição deste estudo, ao oferecer uma visão qualitativa da percepção dos alunos sobre a metodologia, e sobre a influência de seus colegas de equipe. Logo, para compreender melhor a opinião dos alunos sobre a suposição inicial desta pesquisa, que considera que existem influências positivas ou negativas entre os alunos de diferentes estilos de aprendizagem, foram realizadas entrevistas individuais.

Para avaliar os resultados das entrevistas foi utilizado o método de análise de conteúdo, 
método definido por Bardin (2006) como um conjunto de técnicas que analisam a comunicação utilizando procedimentos metodológicos para descrever o conteúdo daquilo que está sendo estudado. Essa técnica de análise de conteúdo permite certo grau de diversificação quanto aos conceitos e metodologias que são aplicados por diferentes autores, de modo que este estudo se utilizou como base o autor mais citado em pesquisas que adotam este modelo: BARDIN (2006). Segundo o autor, para a implementação desta técnica existem três etapas: 1) a préanálise: consiste em uma espécie de organização do trabalho, começando por uma fase chamada de leitura flutuante dos documentos, para que depois sejam elaborados indicadores para orientar a interpretação do material; 2) Exploração do material: esta segunda fase consiste na identificação de partes do texto, neste caso recortes da transcrição das entrevistas que serão categorizados e agrupados; 3 ) Tratamento dos resultados: a terceira fase deste processo se baseia na interpretação dos dados identificados na etapa anterior, fazendo a inferência sobre a suposição inicial levantada como objetivo da pesquisa.

\section{RESULTADOS}

Após a identificação dos estilos de aprendizagem dos alunos, estes foram analisados conforme seus estilos. Neste tópico os resultados obtidos são apresentados e comparados com o que se encontra na literatura disponível sobre o tema. Foi identificado um perfil bem distinto entre as duas turmas, enquanto a turma da UCAM possui a maioria de alunos no estilo "Divergente", a turma do CEFET tem maioria
"Acomodador". Comparando com uma pesquisa semelhante, curiosamente as amostras das duas turmas divergem da amostra de Souza et al (2013), quando também foram analisados alunos de administração e o resultado apresentado foi: 46\% de Assimiladores, 23\% de divergentes, $16 \%$ de Convergentes e 15\% de Acomodadores.

Considerando os critérios mencionados anteriormente, dez alunos foram escolhidos e entrevistados pelo professor de acordo com seus respectivos estilos de aprendizagens. O tamanho da amostra também levou em consideração conceito de saturação teórica (GLASER; STRAUSS, 1967), em que se decide não incluir novos participantes na avaliação de uma determinada pesquisa quando se percebe que as respostas já estão se repetindo e que não há praticamente nenhuma contribuição relevante de novos entrevistados.

Analisando um pouco mais detalhadamente, percebe-se que a turma da UCAM possui $69 \%$ de alunas do sexo feminino, enquanto que a turma do CEFET possui predominância do sexo masculino (60\%). Este perfil de alunos difere do que foi apresentado por Madkur, Mrtvi e Lopes (2008). Na ocasião, os autores tinham identificado em sua amostra que os estilos Assimilador e Convergente eram os mais comuns entre as mulheres, o Assimilador sendo mais predominante entre os homens, e o estilo Divergente o menos representativo (com apenas 9\%). Ou seja, diferente da amostra de Madkur, Mrtvi e Lopes (2008), a amostra deste estudo sinaliza que não é possível estabelecer uma correlação direta entre o sexo e o estilo de aprendizagem de um aluno, o que de certa forma reforça a importância do trabalho de Kolb (1999) ao desenvolver o inventário de estilos (IEA). 
Resgatando o objetivo principal: compreender a relação entre os estilos de aprendizagem dentro de cada equipe numa disciplina de simulações empresariais, verificando se há indícios de que o aprendizado de um aluno pode ser influenciado pelo perfil de aprendizagem de outro integrante da mesma equipe. Vale destacar que o foco neste momento são as relações individuais, e não o comportamento geral da equipe. Além disso, no estudo realizado por Madkur, Mrtvi e Lopes (2008), os autores demonstraram através de índices quantitativos que há similaridade no comportamento das equipes no processo de análise e tomada de decisão, independentemente de ser uma equipe heterogênea ou homogênea.

Considerando que os estilos de aprendizagem configuram uma categorização das entrevistas, para tornar possível avaliar se realmente há influência das preferências de aprendizado de um aluno sobre o nível de aprendizado dos outros integrantes da equipe, para melhor descobrir a opinião dos alunos sobre estas influências foram criadas subcategorias nas quais foram abordados os temas centrais das entrevistas: a metodologia; a equipe; o aprendizado. O objetivo de separar as respostas nestes três temas é verificar sua coerência, e em alguns casos analisar mais profundamente a opinião do aluno. Os resultados foram apresentados nos quadros a seguir, com base nos modelos de Hoffman-Câmara (2013), apresentando a transcrição fiel (ipsis verbis) dos trechos mais relevantes das entrevistas.

\subsection{Acomodadores}

Os alunos da categoria "Acomodador" apresentaram um comportamento bem favorável à metodologia de jogos de negócios, demonstrando interesse em sua aplicabilidade prática ao invés das aulas teóricas, reforçando suas características mais intuitivas destacadas por Cerqueira (2008). No que se refere ao relacionamento entre os participantes de cada equipe, nenhum dos alunos entrevistados apontou qualquer tipo de influência de algum outro integrante da equipe em seu aprendizado, independente do estilo de aprendizagem de seus colegas. Sobre preferir o aprendizado sozinho ou em equipe, houve uma divergência: o aluno 3 teve uma experiência ruim com sua equipe, e isso o fez pensar que a equipe não contribuía para seu aprendizado. No entanto, este mesmo aluno concordou que seria interessante para seu aprendizado se na equipe houvesse alguém com conhecimentos mais específicos em planilhas e cálculos, sinalizando que sua opinião pelo aprendizado sozinho tinha especial relação com a falta de comprometimento de seu colega. Portanto, pode-se dizer que ficou claro nas declarações dos três alunos do estilo Acomodador que eles acreditam que seria melhor trabalhar com uma equipe com habilidades complementares, mais interessada e participativa. $\mathrm{O}$ resultado deste primeiro estilo de aprendizagem revela que apesar de os alunos perceberem que o aprendizado em equipe é maior do que se estivessem sozinhos, não há indícios de que o estilo de um aluno possa influenciar o aprendizado de seus colegas de equipe.

"Os que têm um excessivo componente 'acomodador' podem usar sua energia em melhorias triviais em seu trabalho, que podem resultar em um grande 
fracasso ou algo equivocado. Intuitivos, resolvem os problemas por ensaio e erro".

(CERQUEIRA, 2008).

\subsection{Divergentes}

Os alunos classificados como "Divergentes" também se apresentaram muito satisfeitos com a metodologia, destacando como principal ponto forte as aulas mais dinâmicas do que as aulas tradicionais. Sobre o relacionamento com suas respectivas equipes, os alunos divergentes não tiveram experiências similares, pois enquanto uma aluna considerou ótima a experiência com suas colegas de equipe (uma equipe somente com alunas e com estilo Divergente), os outros alunos do estilo Divergente tiveram colegas de equipe que não participaram muito nas decisões. Vale destacar que nas duas equipes em que ocorreram estes problemas, além dos alunos entrevistados, uma equipe possuía quatro alunos do estilo Acomodador, e a outra equipe possuía dois Acomodadores e um Assimilador. Mesmo com estes problemas de equipe os alunos entrevistados não fizeram referência à questão levantada inicialmente por esta pesquisa, sobre o estilo de aprendizagem de um aluno influenciar o aprendizado de outro aluno.

Apesar de não ter tido uma associação clara entre os perfis de aprendizagem, diante da predominância de alunos Acomodadores nas equipes com o mesmo problema, é possível que exista alguma interferência negativa entre os estilos Divergente e Acomodador. Talvez a dificuldade de se relacionar na mesma equipe esteja associada ao fato de que, segundo Kolb (1999), os Divergentes baseiam suas decisões em experiências concretas; enquanto que os
Assimiladores são mais intuitivos, segundo Cerqueira (2008).

Por fim, sobre o aprendizado sozinho ou em equipe, não houve unanimidade sobre o tema com este grupo, talvez por influência das experiências em equipe, conforme anteriormente mencionado. Assim, enquanto um aluno (aluno 10) acredita que o aprendizado em equipe é essencial para seu futuro profissional, outro aluno (aluno 5) alegou que sua equipe em nada contribuiu para seu aprendizado. Este, no entanto, reconhece que aprenderia mais se a equipe fosse mais participativa e dividisse as tarefas. Outro aluno (aluno 2), do mesmo perfil de aprendizagem, entende ser uma questão de preferência pessoal sua, trabalhar só.

\subsection{Assimiladores}

A categoria seguinte, dos alunos “Assimiladores", manteve o padrão de resposta dos entrevistados sendo favorável sobre a metodologia de jogos de negócios, entretanto estes alunos contrariaram Cerqueira (2008) ao destacar a relevância da simulação como uma aplicação prática do que será vivenciado por eles no mercado de trabalho. Sobre a interação nas equipes, esta categoria ficou prejudicada porque os dois alunos entrevistados tiveram equipes com pouca participação na disciplina. Em uma das equipes, além do aluno de estilo Assimilador, havia dois alunos do estilo Acomodador, enquanto que na outra equipe havia um Acomodador e um Divergente, além do aluno entrevistado. Segundo os Assimiladores, a pouca participação pode ser reflexo tanto do grau de interesse pela abordagem em si, como pela falta de tempo em função do vasto tempo exigido pelo 
trabalho de conclusão de curso que é feito em paralelo com esta disciplina.

Neste grupo novamente não há uma afirmação explícita dos entrevistados sobre algum aluno influenciar diretamente, mas podese perceber nas respostas do aluno 4 que sua equipe não ouvia sua opinião, de modo que preferia que estivesse sozinho na simulação. Esta equipe foi composta por dois alunos do estilo Acomodador e um do Estilo Assimilador, repetindo os indícios do grupo anterior e sinalizando que ao invés de existir um problema na relação de um estilo com o outro, talvez a dificuldade esteja relacionada a um comportamento específico ainda não identificado do estilo de aprendizagem Acomodador em uma disciplina como esta. Segundo Cerqueira (2008), a principal característica do estilo de aprendizagem Acomodador é tomar as decisões por instinto e não usar muitas análises complexas, enquanto que os Assimiladores podem exagerar nas reflexões e ter dificuldades em suas aplicações práticas. Não é possível afirmar seja este comportamento específico que causou os problemas na equipe analisada, mas é factível pensar neste embate entre um aluno mais reflexivo e o outro mais intuitivo.

Vale destacar, quanto às dificuldades atribuídas à realização do TCC (Trabalho de Conclusão de Curso) no mesmo período que esta disciplina, que as outras equipes também enfrentaram essa dificuldade. O mais provável é que o problema nesta equipe esteja mais relacionado a problemas pessoais ou à falta de interesse. Quanto ao aprendizado, esta categoria manifestou preferência pelo trabalho individual. Possivelmente influenciados pelas experiências ruins em suas equipes, os dois alunos deste estilo de aprendizagem afirmaram que sozinhos se sentiriam na obrigação de ver tudo o que a empresa precisava, e que consequentemente aprenderiam mais.

\subsection{Convergentes}

A última categoria analisada foi a dos alunos "Convergentes". Essa foi a categoria menos presente nas turmas analisadas, dificultando a seleção de mais alunos para entrevistas. Mesmo assim os alunos identificados como "Convergentes" se mostraram favoráveis à metodologia baseada em jogos, por evidenciar uma experiência mais generalista, abordando diversas áreas de uma empresa.

No que se refere ao dia-a-dia com suas respectivas equipes, novamente não houve nenhuma declaração explícita de que um aluno influenciou mais o aprendizado do outro, mas é possível perceber que na primeira equipe o aluno Assimilador se destacou mais que os demais integrantes da equipe (Convergente e Divergente). Por outro lado, na segunda equipe o aluno que mais se destacou era do estilo Divergente e fazia a maioria das atividades sozinho, enquanto que os demais integrantes da equipe se acomodaram (todos do estilo Convergente). Através dos estilos de aprendizagem não foi possível encontrar explicações para estes alunos se destacarem, mas baseado nas entrevistas acredita-se ser influência do interesse e maior disponibilidade de tempo destes alunos. Diante de uma amostra tão pequena, e da variabilidade dos estilos encontrados nestas equipes, fica mais difícil dizer que há algum indício da influência dos estilos de aprendizagem neste grupo. Talvez sinalize apenas que este estilo de aprendizagem não lida 
muito bem com uma pessoa tomando a frente da equipe, mas para afirmar isso seria necessário um estudo mais profundo e com uma amostra maior.

Sobre o aprendizado em grupo ou individual, o resultado ficou dividido entre um aluno que acredita mais no seu crescimento se estivesse sozinho porque não ficaria acomodado e teria que se obrigar a fazer tudo, e outro, identificado como convergente, que afirmou gostar muito de trabalhar em equipe, valorizando a opinião dos outros no seu aprendizado.

\subsection{Sumário dos Resultados}

Consolidando as análises das quatro categorias apresentadas anteriormente, pode-se extrair algumas informações relevantes:

Apesar da unanimidade entre os alunos entrevistados sobre a metodologia, a suposição indicada no objetivo principal só foi confirmada no que se refere ao estilo Acomodador, que teve alguns problemas com o estilo Divergente. $\mathrm{Ou}$ seja, o único indício percebido nesta amostra é que possivelmente estes dois estilos (Acomodador e Divergente) não se relacionem muito bem na mesma equipe. De certa forma este resultado surpreende, uma vez que o estilo Divergente gosta de analisar as informações por diferentes pontos de vista (KOLB, 2009), e isso facilitaria a relação com outro estilo. Todavia, o estilo Acomodador que costuma se basear em seus instintos talvez tenha dificuldades de convencer os integrantes de sua equipe em seguir suas opiniões.

Além disso, apesar de não encontrar muitas relações entre os perfis de aprendizagem, ficou clara a opinião da maioria dos alunos entrevistados a percepção de que se aprende mais com estas atividades de trabalho em equipe do que com as de caráter individual. Portanto, até pode-se afirmar que os resultados obtidos confirmam as ideias de Oliveira e Sauaia (2011) sobre o desenvolvimento de habilidades interpessoais através desta metodologia, mas não foi identificada interferência dos estilos de aprendizagem de Kolb (1984), sinalizando que novos estudos devam ser realizados sob diferentes linhas de pesquisa para auxiliar na construção de uma equipe ideal.

Outro ponto relevante identificado pelos alunos como dificultando o aprendizado é a falta de interesse de alguns alunos nos momentos em que o professor lhes dá mais autonomia para tomar as decisões na simulação, algo que já tinha sido identificado por Silva et al. (2012) e continua sendo um grande desafio aos professores. Uma sugestão para novas pesquisas deste tema, é realizar entrevistas com todos os alunos após a simulação, com o objetivo geral de ouvir suas percepções sobre seu aprendizado na simulação; mas especificamente com os alunos considerados com falta de interesse, tentar identificar quais os problemas vivenciados durante a simulação para tentar identificar os motivos do desinteresse.

No sentido positivo, os alunos entrevistados identificaram apenas um elemento que poderia contribuir para seu melhor aprendizado naquele grupo: as habilidades técnicas com planilhas e cálculos financeiros, que teriam feito muita falta em algumas equipes.

\section{CONSIDERAÇÕES FINAIS}

O tema Jogos de Negócios é bastante trabalhado atualmente pelo mundo inteiro no desenvolvimento de novas metodologias e 
tecnologias de ensino, e certamente continuará evoluindo constantemente. Nesta pesquisa, buscou-se operacionalizar uma contribuição dos estudos da psicologia sobre a aprendizagem vivencial para melhor compreender as relações dos alunos dentro de uma equipe durante a simulação.

A suposição inicial era de que através dos perfis de aprendizagem de Kolb (1984) seria possível identificar se havia alguma influência de um aluno no aprendizado de outro integrante da mesma equipe. Para isso, foram analisadas duas turmas do oitavo período do curso de graduação em administração, inicialmente através do inventário de Kolb (1999), para identificar os estilos de aprendizagem de cada aluno. Depois de alguns meses participando da simulação, alguns alunos foram selecionados para a fase de entrevistas qualitativas, de acordo com seus respectivos estilos de aprendizagem e grau de participação na disciplina.

Contrariando os resultados de Dias et al. (2013) e de Butzke (2017), que identificaram em seus estudos opiniões opostas entre os alunos do tipo ativo e os do tipo reflexivo, esta pesquisa não encontrou nenhuma diferença entre a percepção dos alunos sobre a qualidade do método do ensino baseado em jogos, uma vez que todos os estilos de aprendizagem ficaram satisfeitos e elogiaram a metodologia.

Apesar de a relação entre os alunos Acomodadores e os Divergentes ter sinalizado sinalizar algum tipo de incompatibilidade entre os estilos de aprendizagem, os resultados não são significativos para afirmar qualquer tipo de correlação negativa. Portanto, pode-se dizer que o principal resultado desta pesquisa foi a não identificação de influência dos estilos de aprendizagem de Kolb na experiência de aprendizado dos alunos no curso de administração. Para descobrir se os indícios encontrados neste estudo são significativos ou não, recomenda-se que sejam realizados novos estudos considerando uma amostra maior.

Uma sugestão para uma pesquisa complementar sobre o tema é avaliar a qualidade das equipes de acordo com sua composição com base nos estilos, a exemplo do que foi feito por Madkur, Mrtvi e Lopes (2008), mas com um enfoque diferente, utilizando uma amostra maior e uma metodologia quantitativa para criar um índice de similaridade na equipe. Por exemplo, utilizando o plano cartesiano de Kolb (2009) para identificação dos estilos, seria possível somar os valores de "CA-EC" e "EA-OR" dos integrantes da equipe e criar um perfil único da equipe, e com base neste indicador seria possível calcular a distância entre o perfil de uma equipe para o perfil de outra equipe. Para complementar poderiam ser realizados dois testes de avaliação do conhecimento, que seriam aplicados individualmente, sendo um no início e outro no final, com o objetivo de quantificar o aprendizado dos alunos após a simulação.

Apesar dos resultados não terem sido favoráveis à hipótese levantada, na maioria das relações entre os estilos de aprendizagem, as entrevistas indicaram a possibilidade de que realmente seja factível que outras variáveis que não sejam os estilos de aprendizagem possam influenciar a interação entre os participantes de uma equipe, principalmente se as análises forem mais dedicadas às habilidades e competências técnicas dos alunos, como suas habilidades com planilhas de Excel e cálculos financeiros. 
No âmbito da pesquisa qualitativa, novos estudos poderiam replicar esta mesma pesquisa sob a ótica de outros estilos de aprendizagem como os de Keirsey e Bates (1984), ou de Felder e Silvermann (1988). No âmbito da pesquisa quantitativa, pode ser desenvolvido algum tipo de teste para medir através de uma escala quanto o aluno percebe que cada um de seus colegas contribuiu para seu aprendizado.

Por fim, acredita-se que este estudo apresenta uma significativa contribuição para o aprimoramento não somente da disciplina jogos de negócios, mas de uma maneira geral sobre o relacionamento interpessoal entre as pessoas que precisam trabalhar em equipe. Considerando que a metodologia baseada em jogos é uma simulação do ambiente empresarial, não é difícil imaginar que este resultado seja aplicável ao relacionamento de uma equipe dentro de uma empresa, e por este motivo as conclusões podem ajudar os gestores a obter melhores resultados. O principal problema identificado nas entrevistas, a falta de interesse, também ocorre diariamente em diversas empresas que possuem funcionários insatisfeitos. Os resultados apresentados nesta pesquisa reforçam a linha dos autores que estudam o fator motivacional no âmbito da gestão de pessoas. Além disso, empresas que atuam com equipes multifuncionais podem perceber melhor a eficácia de se montar uma equipe com habilidades complementares, conforme foi sugerido pelos alunos nas entrevistas, sugerindo que isso faça parte do planejamento dos recursos humanos que serão utilizados, podendo interferir no processo de seleção de profissionais.

\section{REFERÊNCIAS}

ABNT: INSTITUTO NACIONAL DE ESTUDOS E PESQUISAS EDUCACIONAIS ANÍSIO TEIXEIRA, Sinopse Estatística da Educação Superior 2015. Brasília: Inep, 2016. Disponível em: $<$ http://portal.inep.gov.br/basica-censo-escolarsinopse-sinopse>. Acesso em: 21 ago. 2017.

ALVES, P. V. Jogos e Simulações de Empresas. Rio de Janeiro, Alta Books. 2015

BARDIN, L. Análise de conteúdo. Ed.70, Lisboa. 2006.

BOUZADA, M. A. C. . LABORATÓRIO DE LOGÍSTICA: testando o tradeoff de compras. Revista da Universidade Vale do Rio Verde, Três Corações, v. 15,2017

BUTZKE, M. A., ALBERTON, A. Estilos de aprendizagem e jogos de empresa: a percepção discente sobre estratégia de ensino e ambiente de aprendizagem. REGE, Revista de Gestão v. 24, 2017.

CERQUEIRA, T. Estilos de aprendizagem de Kolb e sua importância da educação. Revista Estilos de Aprendizaje, v1, n1, 2008.

DIAS, G. P. P; SAUAIA, A. C. A; YOSHIZAKI, H. T. Y. Estilos de aprendizagem Felder- Silverman e o aprendizado com jogos de empresa. Rev. Adm. Empres. [online]. V.53, 2013.

FELDER, R.M.; SILVERMAN, L.K. Learning and teaching styles in engineering education. Engineering Education, v. 78 n 7, p. 674-681, abr.1988. Disponível em: Acesso em: jul. 2016

GLASER, G., STRAUSS, A. The discovery of grounded theory: strategies for qualitative research. Aldine de Gruyter, New York. 1967.

HOFFMAN-CÂMARA, R. Análise de conteúdo: da teoria à prática em pesquisas sociais aplicadas as organizações. Revista Interinstitucional de Psicologia, jul-dez, 2013.

KEIRSEY, D; BATES, M. Character \& Temperament Types. $4^{\mathrm{a}}$ ed. Del Mar, Prometheus Book Company, 1984.

KOLB, D. Experiential learning. Englewood Cliffs, New Jersey: Prentice Hall. 1984.

KOLB, D. Learning style inventory version 3: technical specifications. Boston: Hay/McBer, 1999.

KOLB, A. Y. \& KOLB, D. A. The learning way: méta-cognitive aspects of experiential learning. Simulation \& Gaming: An Interdisciplinary Journal. 2009. 
KOLB, d.; BOYATZIS, R. \& MAINEMELIS, C. (2001). Experiential learning theory: previous research and new directions. In: Sternberg, R. \& Zhang,L. (Ed.). Perspectives on cognitive learning, and thinking styles. Mahwah/NJ: Lawrence Erlbaum Associates.

LACRUZ, A. J. ; VILLELA. L. E. . Jogos de empresas como instrumento de capacitação de graduandos em Administração: uma análise à luz da sociedade pós-industrial. In: Encontro Nacional dos cursos de Graduação em Admninistração, 16, 2005, Belo Horizonte. Anais do 16 EnANGRAD, 2005.

MADKUR, F. N. ; LOPES, P. ; MRTVI, V.O. .

Estilos de Aprendizagem e Constituição de Equipes: Um Estudo no Contexto dos Jogos de Empresas. In: XXXII EnanPad/2008, 2008, Rio de Janeiro. XXXII EnanPad/2008, 2008.

MOTTA, G.; MELO, D.; PAIXÃO, R. O Papel do Envolvimento do Aluno no Aprendizado com Jogos de Empresas. In: Encontro de Ensino e Pesquisa em Administração e Contabilidade (ENEPQ), Curitiba. Anais: ANPAD, 2009.

MOTTA, G. da S.; MELO, D.R.A.de; PAIXÃO, R.B. $\mathrm{O}$ jogo de empresas no processo de aprendizagem em administração: o discurso coletivo dos alunos. Rio de Janeiro: RAC, v.16, n.3, art.1, Mai/Jun 2012

OLIVEIRA, M. A.; SAUAIA, A. C. A. Impressão Docente para Aprendizagem Vivencial: Um Estudo dos Benefícios dos Jogos de Empresas.

Administração: Ensino e Pesquisa, v12, 2011.

PEREIRA, M. A. Ensino-Aprendizagem em um contexto dinâmico: o caso de planejamento de transportes. São Carlos: UFSC, 2005.

RANDEL, J. M., MORRIS, B. A., WETZEL, C. D., $\&$ WHITEHILL, B. V. The effectiveness of games for educational purposes: A review of recent research. Simulation \& Gaming, 23(3), 261-276, (1992).

RODRIGUES, C. R., SARRAPIO, L.P. As contribuições do xadrez para o processo de ensinoaprendizagem: aspectos sociais e pedagógicos do jogo na escola. Revista da Universidade Vale do Rio Verde | v. 16 | n. 1 | jan./jul. 2018.

SAUAIA, A. C. A.. Jogos de empresas: aprendizagem com satisfação. Revista de Administração. São Paulo, jul./set., 1997.

SILVA, A. B., LIMA, T. B., SONAGLIO, A. L. B., \& GODOI, C. K. Dimensões de um sistema de aprendizagem em ação para o ensino de administração. Revista Administração: Ensino e Pesquisa, 2012.

SOUZA, G. H. S. ; LIMA, N. C. ; COSTA, A. C. S ; SANTOS, P. C. F. ; PONTES JÚNIOR, J. F. V. ; PENEDO, A. S. T. . Estilos de aprendizagem dos alunos versus métodos de ensino dos professores do curso de administração. In: XXXVII EnANPAD, 2013, Rio de Janeiro. XXXVII Encontro da ANPAD, 2013.

VALENTE, A. M. et al. Qualidade e Produtividade nos Transportes. São Paulo, Cengage Learning, 2008.

\begin{tabular}{l}
\hline Paulo Henrique Pinho de Oliveira \\
Mestre, professor do curso de graduação em \\
administração no CEFET-RJ.
\end{tabular}

Marco Aurélio Carino Bouzada
Doutor, professor permanente do Mestrado em
Administração e Desenvolvimento Empresarial da
UNESA

